tion and stupor. The patient lies for a period varying from six to sixteen hours in a heavy sleep, from which he is with difficulty aroused, and then only to sleep again. The skin is hot; pulse 100 ; the tongue is of a bright-red; drink is taken with avidity, if offered, but only to be immediately returned. And now the important question is put, "Is the throat sore?" The answer is always the same-" Not in the least." This reply, to a physician inexperienced in the horrible malady, may be fatal to the patient. The diagnosis is that this is not a case of diphtheria. On the other hand, the experienced man expects this reply; he forthwith carefully examines the throat, and then he sees the disease. In this early stage, the tonsils, the soft palate, and the back of the pharynx present a bright shining red appearance. The small vessels are not seen indii. Jually injected, as in many forms of sore-throat, but the appearance is as though the parts had been brightly painted and then varnished. Hanging from the velum to the tongue is seen, in this stage, a transparent film of a tenacious fluid, which is burst by expiration, sending its particles over the mouth and the instrument used to depress the tongue. The next moment a similar curtain is formed. After a period varying from six to sixteen hours, the condition of the patient materially changes. The stupor has passed off, and delirium, often of a violent character, takes its place; there are the usual symptoms of cerebral excitement, and the fever runs high; breathing is quickened; the voice is changed to a thick yet shrill tone; there is a short, dry congh; (in children, evidences of coming croup;) the neck is puffy and blushed; the tongue is coated with a white fur, and all those parts hitherto so brilliantly red are thickly spotted with a whitish substance, which, in a wonderfully short period, conglomerates, and forms one thick, plastic deposit, which in time may cover the whole palate to the teeth, so that the appearance, on opening the mouth, is as though it were lined with plaster-of-Paris. The violent delirium then subsides; the powers of life fail rapidly; the horrible sensations of choking and suffocation come on; the sufferer tears at his neck with his nails, and tries to tear open his mouth, yet full power of swallowing still continues, and he greedily gulps anything given him in the shape of drink; large livid spots form on the extremities, amounting sometimes to purpura; the diarrhoea of a white and offensive matter is in cessant; muttering delirium comes on, and in a long tetanic convulsion death closes the scene.

This is a truthful picture, drawn from realities, of how a previously strong and healthy man may, in six days or less, cease to be.

Taking the above as a fair example of diphtheria in its most marked and deadly aspect, as I have seen it, we get the resemblance to it more or less in all minor cases. We must not expect to meet with all the symptoms in every case, but the condition of the throat is invariable. Whether that condition goes on to the second stage depends on the severity of the poison or the success of the treatment adopted. In all cases where there is either nausea or vomiting, followed by drowsiness, the throat ought to be examined, and if the redness and the "glassy curtain" appear, the immediate use of the proper appliances may, $I$ am quite certain, save many valuable lives.

There has been considerable confusion with respect to scarlet fever and diphtheria. Some have contended for the identity of the two, maintaining that those cases in which no rash appeared were to be considered as "suppressed scarlet fever." To combat this view, it will be sufficient, I think, to draw attention to the great difference in the symptoms I have de. scribed from those of scarlatina, and to state the fact of its having been my painful experience to have attended families some members of which have been swept off by scarlet tever with diphtheria, whilst other members, who had previously suffered from scarlet fever in a severe form, were now attacked with true diphtheria. That scarlatina invites diphtheria is very manifest, but that the diseases are perfectly distinct and different is equally certain

Now as to the treatment. This matter has been so skilfully discussed in the columns of The LANCET that I need not enter much into detail. The constant attention to the condition of the throat should be our first care, the second is to resist the "tendency to death." By skilful personal application of strong solution of caustic to the glazed and reddened parts, the fungoid matter may not appear, or if formed, may be separated from the surface and brought away, and thus the horrors of the dis ease prevented. Still, even then, there is much to be done in supporting the powers of the constitution, so as to give it assistance in eliminating the terrible poison from the system.

Bearing these two essentials of treatment constantly in mind, I know of no epidemic disease we may be more hopeful about than this. Terrible as it is to behold-its very name spread. ing dismay and dread to all around, yet its severity and fearful characteristics seem to succumb to the judicious and speedy treatment of the attentive physician with a kindness hardly to be expected.

Diphtheria is no respecter of person, age, condition, rank, or temperament. Should it become more seriously epidemic than it has been, no doubt it will mow down many of those unhappy people whose hard necessities oblige them to live in the overcrowded and ill-ventilated courts and alleys of our large cities. In such cases it will clearly be the mission of our profession, as in visitations of cholera, to go to the disease, and not to let it come to us.

Bristol, August, 1859.

ON

\section{A CASE OF SANGUINEOUS TUMOUR OF THE LABIUM.}

BY JAMES GILMOUR, M.D., L.R.C.P., \&c., PHYSICIAN-ACCOUCHEUR TO THE LIVERPOOI LADIES' CHARITY.

ON the 5th of February last, about five A.M., I was summoned, in great haste, to visit Mrs. M- who, it was stated, had been confined two hours previously of a living child, but the midwife considered that something was wrong, and which she did not understand. I hastened to the place indicated, and, on entering the bed-room, I found the patient lying on her back, her knees drawn up, and apparently suffering from labour pains of an expulsive character; she was deadly pale, and in great anguish.

On gently placing her on the left side for the purpose of making an examination per vaginam, I found an enormous tumour projecting from the vagina, considerably larger than a child's head, involving the whole of the left labium pudendi, mons veneris anteriorly, and anus posteriorly; the colour was intensely black, the surface smooth and shiny, and studded with the hair of the labium.

I carefully examined the tumour, but could with difficulty pass my finger into the vagina; rather high up I found the os uteri, soft and patulous, indicating that labour had taken place. I searched for some rent or abrasion of the vaginal canal, but was unable to discover any. The bearing-down pains were increased by my manipulation. The patient anxiously desired that something should be done for her relief, as her sufferings, she said, were very great. I concluded that the swelling was an effusion of blood in to the labium, though $I$ had never seen such a case before.

Without further delay, I made an incision, about two inches in length, along the tumour, and, with my finger, scooped out about a pint of dark clots of blood, apparently of a venous character. After carefully pressing out the remaining fluid contents, I plugged the vagina with cotton wadding, which happened to be in the room. There was no further infiltration of the swelling; adhesion of the disrupted mucous membrane took place in ten days; and, with the usual care, the woman made an excellent recovery, except that she looked anæmic for a few weeks afterwards.

The previous history of the patient is very brief. She had always enjoyed good health; married at thirty-six; her first labour was good, and she is now (when this accident occurred) about forty. This was her second confinement: her labour was easy; the placenta speedily expelled, and for an hour after she felt pretty well; but, at the end of that time, she expe. rienced slight pains, which were taken for after-pains, until the midwife discovered the vaginal tumour, when she sent for me.

This affection is not often met with, for I do not find any case of the kind recorded in THE LANOET since 1844. To the young surgeon, inexperienced in such matters, it might prove a source of much annoyance, if suddenly confronted with a patient under the above circumstances. The reader will find full details of this strange attack after labour, in Churchill's "Diseases Peculiar to Women" (Sydenham Society), and Dewees' "Diseases of Females" (chap. ii.) Some difference of opinion exists as to the cause of this affection. I am unable, as far as my case is concerned, to throw any additional light on the subject.

Liverpool, August, 1859 . 